\title{
In situ hybridization on whole larvae: a novel method for monitoring bivalve larvae
}

\author{
Marie C. Le Goff-Vitry ${ }^{1,3, *}$, Ariel D. Chipman ${ }^{2}$, Thierry Comtet ${ }^{1}$ \\ ${ }^{1}$ UMR 7144 CNRS UPMC, Station Biologique, BP74, 29682 Roscoff cedex, France \\ ${ }^{2}$ University Museum of Zoology, Downing Street, Cambridge CB2 3EJ, UK \\ ${ }^{3}$ Present address: Cardiff School of Biosciences, Cardiff University, Cardiff CF10 3US, UK
}

\begin{abstract}
Accurate and efficient identification to the species level of early larval stages has long been a problematic step in the study of marine invertebrates, due to the extremely small size of the larvae and their lack of diagnostic morphological characters. It is nonetheless, a prerequisite for any ecological study. As a consequence, a number of molecular approaches, mostly based on the PCR technique, have been developed over the last decade. We developed a method relying on specific rRNA-targeted oligonucleotide probes for in situ molecular hybridization using whole larvae. A colorimetric reaction following the hybridization allows signal detection with a light microscope. A total of 9 probes have been developed, targeting the species that are major components of benthic communities in several European bays. The method can be applied to roughly sorted wild plankton samples, and some steps could be automated. It is relatively inexpensive to implement and does not require costly equipment or expensive staff training. The overall larval morphology is preserved, allowing visual inspection. The quantitative aspect of the approach is another asset. Field-based studies of larval distribution and behaviour are possible applications of the method, as large numbers of samples can be screened to meet the requirements of adequate spatial and temporal coverage. It is also relevant for routine monitoring of target species, such as species of commercial interest, bio-indicators or invasive species.
\end{abstract}

KEY WORDS: Bivalve larvae - Species identification · In situ hybridization · Oligonucleotide probes · 18S rDNA Resale or republication not permitted without written consent of the publisher

\section{INTRODUCTION}

Pelagic larvae represent a decisive phase in the life cycles of many marine animals, playing a fundamental role in population dynamics and connectivity. In the case of many sessile benthic invertebrates, pelagic larvae represent the exclusive dispersal vector. Precise species identification is prerequisite information for larval ecological studies. The identification of marine invertebrate larvae, especially bivalves, remains nonetheless a notoriously difficult target. Early developmental stages of bivalve larvae can measure $<100 \mu \mathrm{m}$, and often lack reliable identification characters (e.g. Rees 1950). M orphology can be used for identification at later developmental stages for some species, but this approach requires rare expertise, and long preparation of samples when scanning electron microscopy is used for precise observation (e.g. Fuller \& Lutz 1989). Larval identification guides are also restricted to particular geographical areas where such descriptive work has been undertaken for commonly occurring species, and no such comprehensive guide is available for European bivalve species (Larsen et al. 2005).

A variety of molecular approaches, including both DNA-based and immunological methods, have been developed over the last decade to facilitate identification of bivalve larvae (reviewed in Garland \& Zimmer 2002). The scope of such methodological developments ranges from one or a few focused species, such as invasive species (Pie et al. 2006) or species of commercial interest - oysters (e.g. M organ \& Rogers 2001), 
scallops (e.g. Frischer et al. 2000, Paugam et al. 2003), surfclams (Bell \& Grassle 1998), cockles (André et al. 1999) and mussels (e.g. Wood et al. 2003, LorenzoA balde et al. 2005) - to a wider range of commonly found species (e.g. Hosoi et al. 2004, Larsen et al. 2005). While single-species focused studies have used varied approaches, such as immunology (e.g. LorenzoA balde et al. 2005), RA PDs (André et al. 1999), microsatellite markers (M organ \& Rogers 2001), RFLPs (e.g. Comtet et al. 2000), dot-blot (e.g. Frischer et al. 2002), PCR amplification and hybridization (Frischer et al. 2000), and multiplex PCR (e.g Wood et al. 2003), identification methods developed for a range of species mainly rely on derivations of 2 PCR methods, viz. RFLP (e.g Hosoi et al. 2004) and multiplex PCR (e.g. Larsen et al. 2005).

In their review, Garland \& Zimmer (2002) describe the ideal identification technique as (1) involving no direct sub-sampling of organisms from a sample, (2) effective for intact organisms, (3) producing a detectable result through image analysis, (4) relatively inexpensive to develop, (5) relatively inexpensive to use and (6) producing accurate and repeatable results. The methodological development towards bivalve larvae identification presented here was designed to take most of these criteria into account.

In situ hybridization coupled with fluorescent detection (FISH) has been successfully applied as an identification method to a variety of microorganisms, including those from the marine environment, allowing visualization and enumeration of microbial populations (reviewed in Amann et al. 1995), planktonic Archaea and bacteria (e.g. DeLong et al. 1999), small phytoplankton (e.g. Tyrrell et al. 1997, Simon et al. 2000), as well as the identification and localization of bacterial symbionts (e.g. Haygood \& Davidson 1997). Application of the methodology to whole invertebrate larvae has been restricted so far to evolution and development research, and has targeted a few marine model species, such as ascidians (e.g. Ueki et al. 1994), sea urchins (e.g.Yaguchi \& Katow 2003), gastropods (Nederbragt et al. 2002), and the oyster Crassostrea gigas (Fabioux et al. 2004).

We show that in situ hybridization can be used to detect specific bivalve larvae from wild plankton samples. The method relies on specific DNA oligo-probes designed from sequences obtained for a partial, variable region of the $18 \mathrm{~S}$ rRNA coding gene. Ribosomal RNA-targeted oligonucleotide probes have become a widely used tool for ecological studies in marine microbiology (reviewed in Amann et al. 1995), as their hybridization target sites, the ribosomes, are numerous in single whole cells, allowing efficient hybridization signal detection. The 18S rRNA gene shows sufficient variation in bivalves to be used for designing species- specific probes (Bell \& Grassle 1998, Frischer et al. 2002, Larsen et al. 2005). The development of the method involved setting up an in situ hybridization protocol using $18 \mathrm{~S}$ oligo-probes applicable to whole bivalve larvae, designing species-specific probes for the bivalve species commonly found in European coastal waters, and checking for a specific, easily detectable signal with the designed probes.

\section{MATERIALS AND METHODS}

The first step of this project was to develop a general protocol for in situ hybridization using whole bivalve larvae collected from wild plankton samples. The aim of this approach was to ensure that any bivalve larva potentially occurring in coastal water samples, whatever its developmental stage or species, could be identified reliably through a detectable hybridization signal. This implied the use of a positive and a negative probe that had already been used for in situ hybridization in previously published studies. This step also led to selection of markers for subsequent specific probe design.

The second step of the project was to build a sequence database to design specific probes. Probe specificity was experimentally assessed through 2 approaches, i.e. detection on dot-blots, using PCR products obtained from adult bivalves as the target, and in situ hybridization using whole larvae collected separately from parents of 4 known species held in hatcheries. In situ hybridization tests were also conducted on samples composed of mixed identified larvae, mimicking simple wild samples.

Development of a protocol for in situ hybridization on whole larvae. Plankton sampling and fixation of bivalve larvae: Plankton was sampled in M orlaix Bay off the northern coast of Brittany (France) $\left(48^{\circ} 40^{\prime} \mathrm{N}\right.$ $3^{\circ} 53^{\prime} \mathrm{W}$ ) using a $63 \mu \mathrm{m}$ mesh size WP2 plankton net. Samples were collected throughout the year; seawater temperatures varied from $8^{\circ} \mathrm{C}$ to $16^{\circ} \mathrm{C}$. Samples were kept in seawater until arrival at the laboratory where veliger-type bivalve larvae were isolated under a dissecting microscope. Larvae were then transferred to a $20 \% \mathrm{M} \mathrm{gCl}_{2}$ muscle relaxant solution in order to ensure valves would be open to allow subsequent probe penetration. A 4\% paraformaldehyde (PFA) in phosphatebuffered saline solution (PBS) was used as a first fixative for $1 \mathrm{~h}$, before transfer to a microtube containing $96 \%$ ethanol at $-20^{\circ} \mathrm{C}$ for long-term storage.

In situ hybridization: The reactions were carried out using $50 \mu \mathrm{m}$ mesh baskets (containing the larvae) placed into cell culture clusters. Samples were first rinsed with gradual series of ethanol/PBT (phosphatebuffered saline containing $0.1 \%$ Tween 20 ) solutions, and then twice in PBT. 
Two hybridization temperatures were tested (50 and $55^{\circ} \mathrm{C}$ ), and 2 concentrations of formamide in hybridization buffer (10 and 50\%). Pre-hybridization was set for at least $1 \mathrm{~h}$ at hybridization temperature, using prewarmed hybridization buffer ( $5 \times$ saline solution citrate buffer (SSC), $0.2 \mathrm{mg} \mathrm{m}^{-1}$ salmon sperm DNA, $0.1 \mathrm{mg}$ $\mathrm{ml}^{-1}$ heparin, $2 \mu \mathrm{ml}^{-1}$ Tween $20,5 \%$ dextran sulfate) containing formamide. Larvae underwent hybridization overnight, using a $1 \mathrm{ng} \mathrm{\mu l}^{-1}$ probe concentration. Two oligonucleotide DNA probes were selected through ProbeBase (Loy et al. 2003). A universal probe, targeting the 18S rRNA of all eukaryotes, EUK516 (Amann et al. 1990), was chosen as a positive control, and a non-specific probe, targeting the $23 \mathrm{~S}$ rRNA of 2 bacterial strains, Candidatus Brocadia anammoxidans and Candidatus Kuenenia stuttgartiensis, A mx1900 (Schmid et al. 2001), was chosen as a negative control. Both were modified with digoxigenin at their 3' end (MWG Biotech).

Three post hybridization washes were performed using hybridization buffer at hybridization temperature, the first for $1 \mathrm{~h}$ and the following 2 for $30 \mathrm{~min}$. Two additional 5 min washes with gentle agitation were carried out with PBT. Larvae were subsequently incubated with a blocking solution (10\% goat serum in PBT) for at least $1 \mathrm{~h}$ prior to overnight incubation at $4^{\circ} \mathrm{C}$ with the same solution containing $1 \%$ Dig-AP conjugate (Roche). Three 10 min washes with gentle agitation were performed with PBT, followed by 2 washes with colour-developing buffer $(100 \mathrm{mM}$ Tris- $\mathrm{HCl}$, $\mathrm{pH}$ 9.5, $100 \mathrm{mM} \mathrm{NaCl}, 50 \mathrm{mM} \mathrm{M} \mathrm{gCl} 2,0.01 \%$ Tween 20). Larvae were incubated with BM Purple AP substrate (Roche) at $37^{\circ} \mathrm{C}$ in the dark until colour development. When a positive signal was detected under the dissecting microscope, the reaction was stopped by PBT washes. Photomicrographs of the larvae were taken using magnifications varying from $100 \times$ to $200 \times$ and using a Nikon Coolpix 4300 camera. The experiments were repeated 5 times to check consistency of results.

Design of species-specific probes. Using the universal primers from Larsen et al. (2005), we sequenced a total of 123 bivalve individuals encompassing 24 species commonly found in European coastal waters. Whenever possible, more than one individual per species was sequenced in order to include intra-specific variability in subsequent analyses.

DNA was extracted using a phenol chloroform protocol, as described in T. Comtet \& M. C. Le Goff-Vitry (unpubl.). Each $25 \mu \mathrm{l} \mathrm{PCR}$ sample included $2 \mathrm{mM}$ $\mathrm{M} \mathrm{gCl}_{2}$ (Euroclone), $1.25 \mu \mathrm{mol}$ of each each dNTP (ABgene), 13 pmol of primers Uni 1304F and Uni 1670R (MWG Biotech), $2.5 \mu \mathrm{l}$ of 10× reaction buffer (Euroclone), 1 unit of Taq Polymerase (Euroclone) and $1.3 \mu \mathrm{l}$ of 1:100 diluted extracted DNA. PCR was performed with a GeneA mp ${ }^{\circledR}$ PCR System 2700 (Applied Biosystems) thermocycler using an initial denaturation at $94^{\circ} \mathrm{C}$ for $4 \mathrm{~min}$, followed by 35 cycles of $94^{\circ} \mathrm{C}$ for $1 \mathrm{~min}$, $57^{\circ} \mathrm{C}$ for $1 \mathrm{~min}, 72^{\circ} \mathrm{C}$ for $1 \mathrm{~min}$, and a final extension at $72^{\circ} \mathrm{C}$ for $7 \mathrm{~min}$. PCR products were visualised on a $2 \%$ agarose gel stained with ethidium bromide and subsequently purified using the Multiscreen ${ }^{\circledR} \mathrm{PCR}_{\mu 96}$ kit (Millipore). Sequencing was performed on an $A B I$ 3100 sequencer using BigDye terminator chemistry (PerkinElmer), following the manufacturer's protocol. Sequencing was done in both directions. The resulting sequences were checked using Chromas Lite 2.01 (Technelysium, Copyright 1998-2005) and combined together with homologous bivalve sequences obtained from GenBank to build a database total of 197 sequences (Appendix 1, available as Supplementary Material at www.int-res.com/articles/suppl/ m343p161_app.pdf).

Winprobe software (Pozhitkov \& Tautz 2002) was used to design species-specific oligo probes using this database. When low sequence resolution did not allow the design of species-specific probes, higher taxonomic levels were targeted. Probe specificity was further tested using BLAST (Basic Local Alignment Search Tool: http://130.14.29.110/BLAST/) and selecting the 'search for short, nearly exact matches' option.

Probe specificity tests by dot-blot. Ideally, all designed probes would be tested through in situ hybridization, using identified larvae from each target species. However, obtaining such larval samples is very demanding in terms of equipment, expertise and time, as it requires conditioning pools of adult bivalves, inducing spawning and rearing larvae at least for a few days. A much more straightforward approach consists of testing probes by dot-blot, using whole 18S PCR products obtained from adult DNA and blotted onto a membrane. This is a common procedure with specific probe development for FISH (fluorescent in situ hybridization; e.g. Edgcomb et al. 1999, Simon et al. 2000). The 9 probes we designed (Table 1 ) were tested against PCR products obtained from a total of $75 \mathrm{bi}-$ valve individuals belonging to 18 different species. Probes were tested individually on membranes containing 8 individuals of Mytilus sp. (Mytilus edulis / Mytilus galloprovincialis complex), 5 of Nucula nucleus, 8 of Ostrea edulis, 6 of Crassostrea gigas, 14 of Veneridae (5 of Venerupis pullastra, 3 of Timoclea ovata, 1 of Tapes rhomboides and 5 of Ruditapes decussatus), 7 of Macoma balthica, 7 of Cerastoderma edule, 7 of Glycymeris glycymeris, 8 of Pectinidae (6 of Pecten maximus and 2 of Chlamys varia), and 1 individual each of the following non-target species: Tellina tenuis, Corbula gibba, Laevicardium crassum, Abra alba and Spisula ovalis. 
Table 1. List of the 18S rRNA targeted DNA oligoprobes with the taxon specifically targeted

\begin{tabular}{|lll|}
\hline Probe name & \multicolumn{1}{c|}{ Probe sequence } & \multicolumn{1}{c|}{ Taxon targeted } \\
\hline Cra-gig-18S & 5'-CGACAGCAATAGATCGGTGA-DIG & Crassostrea gigas \\
Ost-ed-18S & 5'-ACAGTTTCGAGATCGGTGAA-DIG & Ostrea edulis \\
Cer-ed-18S & 5'-TTGACGGCGGGGACGGTATT-DIG & Cerastoderma edule \\
Mac-ba-18S & 5'-GGCAAGGCAATAAGCACGTT-DIG & Macoma balthica \\
Myt-18S & 5'-CCGACGCAAATGGGGATCGG-DIG & Mytilus sp. \\
Nuc-18S & 5'-ACGGACGCATACGGATCCGT-DIG & Nucula sp. \\
Gly-18S & 5'-CCAATGGATCGATGAACTAT-DIG & Glycymeris sp. \\
Pec-18S & 5'-GCAAGGATAAGAGCACGTTG-DIG & Pectinidae \\
Ven-18S & 5'-CGGGGACTCGATAGAGGATC-DIG & Veneridae \\
\hline
\end{tabular}

For PCR amplification of the whole $18 \mathrm{~S}$ gene, we used the universal primers from M oon-van der Staay et al. (2001). Each $25 \mu \mathrm{l}$ PCR sample comprised $2.6 \mathrm{mM}$ $\mathrm{MgCl}_{2}$ (Euroclone), $1.25 \mu \mathrm{l}$ of each dNTP (Abgene), 13 pmol each of primers 328 and 329 (MWG Biotech), $2.5 \mu \mathrm{l}$ of $10 \times$ reaction buffer (Euroclone), 1.25 unit of Taq Polymerase (Euroclone) and $2 \mu \mathrm{l}$ of 1:100 diluted extracted DNA. PCR reactions were performed on a GeneAmp ${ }^{\circledR}$ PCR System 2700 (Applied Biosystems) using an initial denaturation at $95^{\circ} \mathrm{C}$ for $5 \mathrm{~min}$, followed by $34 \mathrm{cycles}$ of $95^{\circ} \mathrm{C}$ for $1 \mathrm{~min}, 55^{\circ} \mathrm{C}$ for $1 \mathrm{~min}$ $30 \mathrm{~s}, 72^{\circ} \mathrm{C}$ for $2 \mathrm{~min}$, and a final extension at $72^{\circ} \mathrm{C}$ for $10 \mathrm{~min}$. PCR products were visualised as before.

Blotting of the PCR products onto a positively charged nylon membrane (Roche) was performed using a Bio-Dot $\circledast$ Microfiltration Apparatus (BioRad) according to the manufacturer's instructions. The blotted membranes were subsequently incubated with hybridization buffer ( $5 \times \mathrm{SSC}, 0.1 \% \mathrm{~N}$-lauryl sarcosine, $0.02 \%$ sodium dodecyl sulfate (SDS) and $0.1 \mathrm{mg} \mathrm{ml}^{-1}$ salmon sperm DNA) for $1 \mathrm{~h}$ at $42^{\circ} \mathrm{C}$ in a minihybridization oven (Appligene). Hybridization was carried out overnight at $42^{\circ} \mathrm{C}$ with a probe concentration of $7 \mathrm{pmol} \mathrm{ml}^{-1}$. A total of 6 post-hybridization washes were performed, including 2 washes with $2 x$ SSC $0.1 \%$ SDS at room temperature for $5 \mathrm{~min}, 2$ washes with $2 \times \mathrm{SSC} 0.1 \%$ SDS at $55^{\circ} \mathrm{C}$ for $10 \mathrm{~min}$, and 2 final washes with $0.5 \times$ SSC $0.1 \%$ SDS at $55^{\circ} \mathrm{C}$ for $20 \mathrm{~min}$. The membranes were then soaked in Buffer 1 $\left(0.1 \mathrm{M}\right.$ Tris $\mathrm{HCl} \mathrm{pH} 7.5,0.1 \mathrm{M} \mathrm{NaCl}, 2 \mathrm{mM} \mathrm{MgCl}_{2}$, $0.05 \%$ Triton 100 ) for $5 \mathrm{~min}$ at room temperature, and then with Buffer $2(0.1 \mathrm{M}$ Tris $\mathrm{HCl} \mathrm{pH} 7.5,0.1 \mathrm{M} \mathrm{NaCl}$, $2 \mathrm{mM} \mathrm{MgCl} 2,0.05 \%$ Triton 100, 2\% Bovine Serum Albumin (BSA)) for $1 \mathrm{~h}$ at room temperature. Incubation with Buffer 1 containing Dig-AP conjugate (1/2000 dilution) (Roche) was carried out for $30 \mathrm{~min}$ at room temperature. Membranes were then washed (with rocking) 3 times with Buffer 1 for $10 \mathrm{~min}$ and then 3 times with Buffer $3(0.1 \mathrm{M}$ Tris $\mathrm{HCl}$ pH 9.5, $0.1 \mathrm{M}$ $\mathrm{NaCl}, 0.05 \mathrm{M} \mathrm{MgCl}_{2}$ ) for $10 \mathrm{~min}$. They were finally incubated with NBT/BCIP (Roche) diluted in Buffer 3
( $1 / 50$ dilution) at $37^{\circ} \mathrm{C}$ in the dark until signal detection. The staining reaction was stopped by rinsing the membranes with Buffer $4(20 \mathrm{mM}$ Tris $\mathrm{HCl} \mathrm{pH} 7.5$, $5 \mathrm{mM}$ ethylenediaminetetraacetic acid (EDTA)). Photographs of the membranes were taken with a Nikon Coolpix 4300 camera. The dot-blot test for each probe was repeated twice in order to check the consistency of the results.

In situ test with designed probes. Larvae from 4 species of commercial interest, for which rearing is possible, were obtained from hatcheries. The specific probes for these 4 species were tested by in situ hybridization. Crassostrea gigas larvae were obtained from Station Expérimentale Ifremer d'Argenton (France), Pecten maximus larvae from Ecloserie du Tinduff (France) and Mytilus edulis and Ostrea edulis from Laboratoire Ifremer La Tremblade (France). C. gigas larvae were at the umboned stage, and their mean size was $184 \mu \mathrm{m}$. Two batches of $P$. maximus larvae were available: the youngest were $8 \mathrm{~d}$ old, with a mean size of $148 \mu \mathrm{m}$; the oldest were $15 \mathrm{~d}$ old and $212 \mu \mathrm{m}$ in mean size. M. edulis larvae were $14 \mathrm{~d}$ old, with a mean size of $224 \mu \mathrm{m}$. O. edulis larvae were $10 \mathrm{~d}$ old, with a mean size of $174 \mu \mathrm{m}$. Fixation was carried out as for larvae isolated from plankton samples.

In situ hybridization tests were carried out using a range of hybridization conditions (hybridization temperatures from $46^{\circ} \mathrm{C}$ to $55^{\circ} \mathrm{C}$, formamide concentrations in hybridization buffer from $10 \%$ to $50 \%$ and

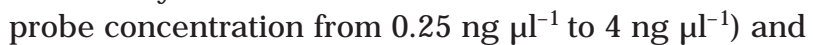
10 individuals per species, for each probe. Cragig-18S, Pec-18S, Myt-18S and Ost-ed-18S probes (Table 1) were tested through in situ hybridization using their respective target larvae, but also using nontarget larvae, in order to check probe specificity.

These probes were also tested through in situ hybridization using 'artificial meroplankton samples' containing a mixture of 10 larvae from each of the 4 species. Morphological characteristics and size differences all owed us to distinguish the different larval species after hybridization. Photographs of the larvae were taken under the microscope using a Nikon Cool pix 4300 camera.

\section{RESULTS}

In situ hybridization using rRNA-targeted oligoprobes on whole bivalve larvae from wild samples

A universal protocol for in situ hybridization on whole larvae applicable to wild plankton samples was 
successfully developed. We obtained a suitable signalto-noise ratio with the universal eukaryotic probe at both hybridization temperatures and formamide concentrations. Bivalve larvae isolated from plankton samples stained strongly with the universal probe, while no staining was observed either with the non-specific probe or with no probe (Fig. 1). The signal was detectable under the dissecting microscope after $1 \mathrm{~h}$ of incubation with the substrate, whatever the size or morphology of the veliger larvae.

\section{Specific oligo-probes}

The lengths of the partial $18 \mathrm{~S}$ sequences obtained varied between 310 and $440 \mathrm{bp}$, and were variable enough to allow the design of species-, or genusspecific probes in most cases (Table 1). Out of a total of 9 designed probes, 4 are species-specific and 3 are genus-specific. When it was not possible to obtain species-specific probes, probes were designed to target the genus level (Mytilus, Glycymeris and Nucula), or the family level, in the cases of Pectinidae and Veneridae.

Probe specificity was first assessed through dot-blot tests, using whole 18S PCR products of approximately $1.5 \mathrm{~kb}$ obtained from adult bivalve DNA. These tests allowed checking the results of in silico specificity analyses. In 2 cases, probes had to be re-designed because cross-hybridization was encountered. The probe initially designed for Ostrea edulis crosshybridized with Mytilus edulis and Crassostrea gigas individuals, and the first probe designed for Nucula cross-hybridized with Cerastoderma edule individuals, despite tentative optimizations (data not shown). Two new probes were therefore designed: Ost-ed-18S and Nuc-18S (See Table 1) and tested through dot-blot. At this stage, all tested probes showed a specific signal (Fig. 2). When testing Nuc-18S, all 5 Nucula nucleus individuals showed a strong hybridization signal, and a very faint signal appeared for one of the 7 Gly- cymeris glycymeris individuals. This result was considered not to compromise the specificity of the probe. The probes targeting the family level (Pec-18S and Ven-18S) showed a positive signal only with the individuals belonging to the species and genera from the targeted family.

An additional batch of specificity tests was performed for 4 probes, viz. Cra-gig-18S, Pec-18S, Myt-18S and Ost-ed-18S through in situ hybridization on identified bivalve larvae from the species Crassostrea gigas, Pecten maximus, Mytilus edulis and Ostrea edulis. A first series consisted of testing each probe separately on each larval species. Results are presented in Fig. 3. Positive signals were detected for all larvae with their respective specific probe. In Fig. 3, the signal-to-background ratio appears weaker on Ostrea edulis larvae, but remains unambiguous under the microscope. The proportion of stained larvae was lower for $M$. edulis (about 70\%); this observation was repeated when using the universal probe (EUK516) (data not shown). For all probes, positive signals were detected over a range of hybridization temperatures (from 46 to $50^{\circ} \mathrm{C}$ ), probe concentrations (from 0.1 to $1 \mathrm{ng} \mathrm{\mu l}^{-1}$ ) and formamide concentrations (from 10 to $50 \%$ ). No cross hybridization was observed.

The second series of in situ hybridization tests included mixtures of larvae from these 4 separate species to constitute an 'artificial meroplankton sample'. The overall conservation of larval morphology and size after in situ hybridization allowed visual identification of each larva to species. Hybridization conditions were optimized for each probe, and the consistency of the results under these conditions was validated by repeating the experiment. The conditions giving the best results for each probe are presented in Table 2, and results are shown in Fig. 4. Such optimizations reduced the occurrence of non-specific signals, which were mainly observed in Ostrea edulis larvae as dark purple, dot-shaped staining localized internally around the digestive gland. This non-specific staining occa-
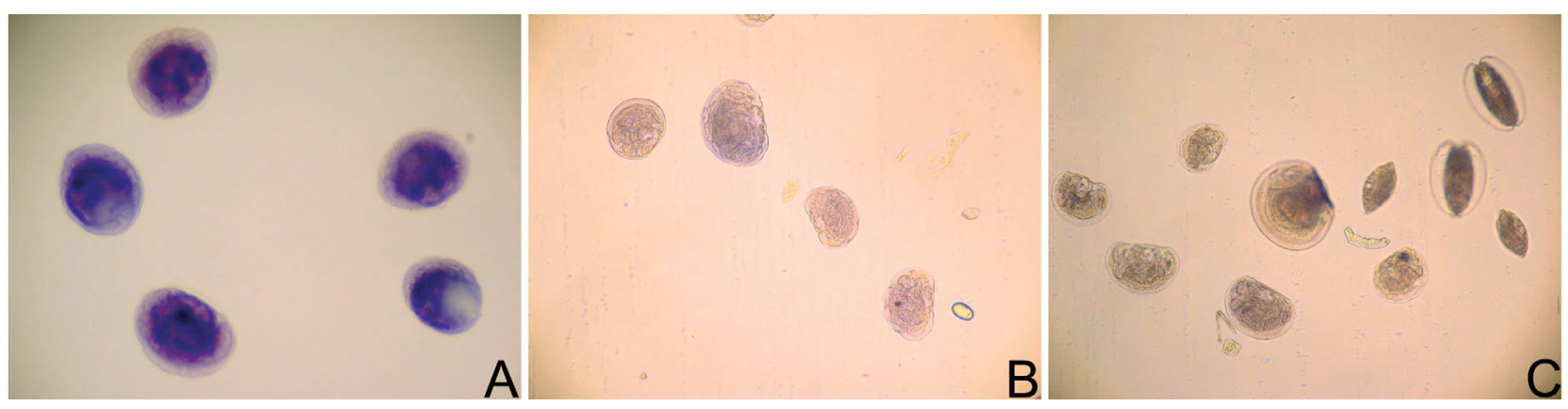

Fig. 1. In situ hybridization on whole bivalve larvae (more than 1 species) isolated from plankton samples with (A) universal oligo-probe, (B) non-specific probe and (C) no probe. Magnification varies from $100 \times$ to $200 \times$ 
$\begin{array}{llllllllllll}1 & 2 & 3 & 4 & 5 & 6 & 7 & 8 & 9 & 10 & 11\end{array}$
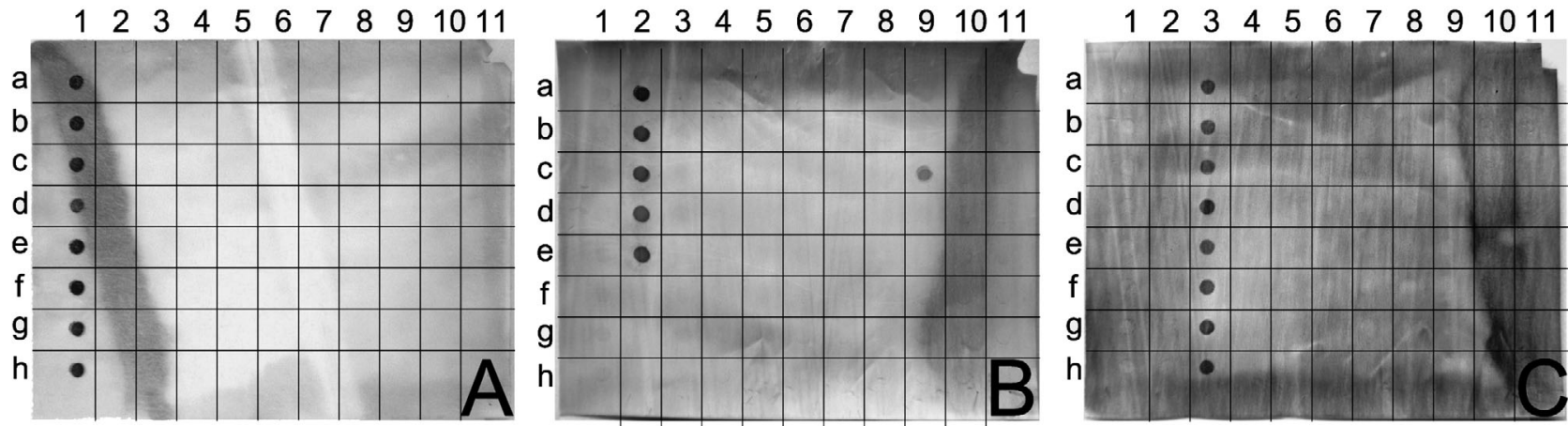

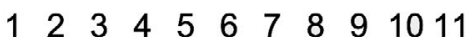

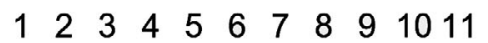

$\begin{array}{lllllllllll}1 & 2 & 3 & 4 & 5 & 6 & 7 & 8 & 9 & 10 & 11\end{array}$
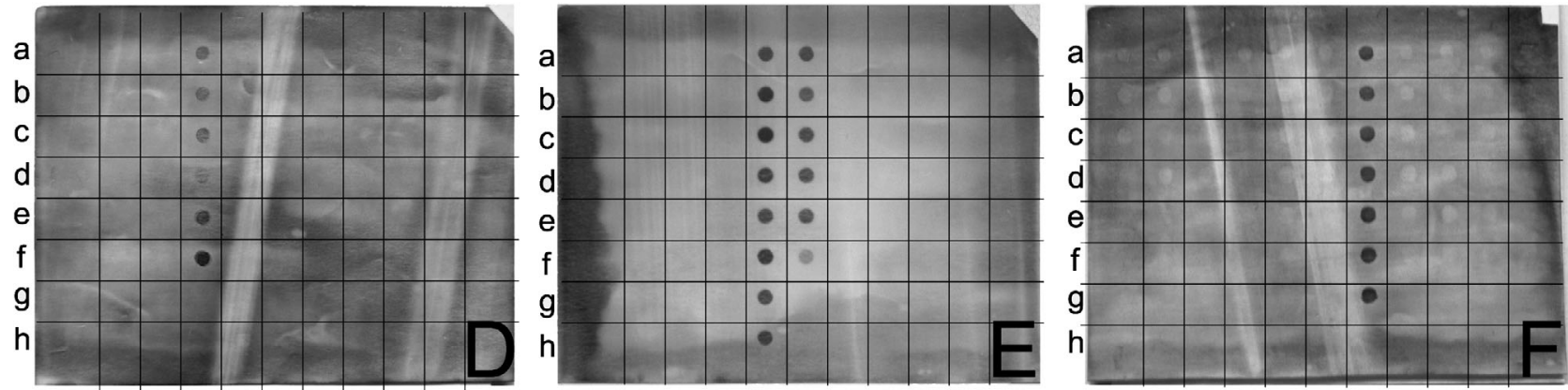

$\begin{array}{lllllllllll}1 & 2 & 3 & 4 & 5 & 6 & 7 & 8 & 9 & 10 & 11\end{array}$
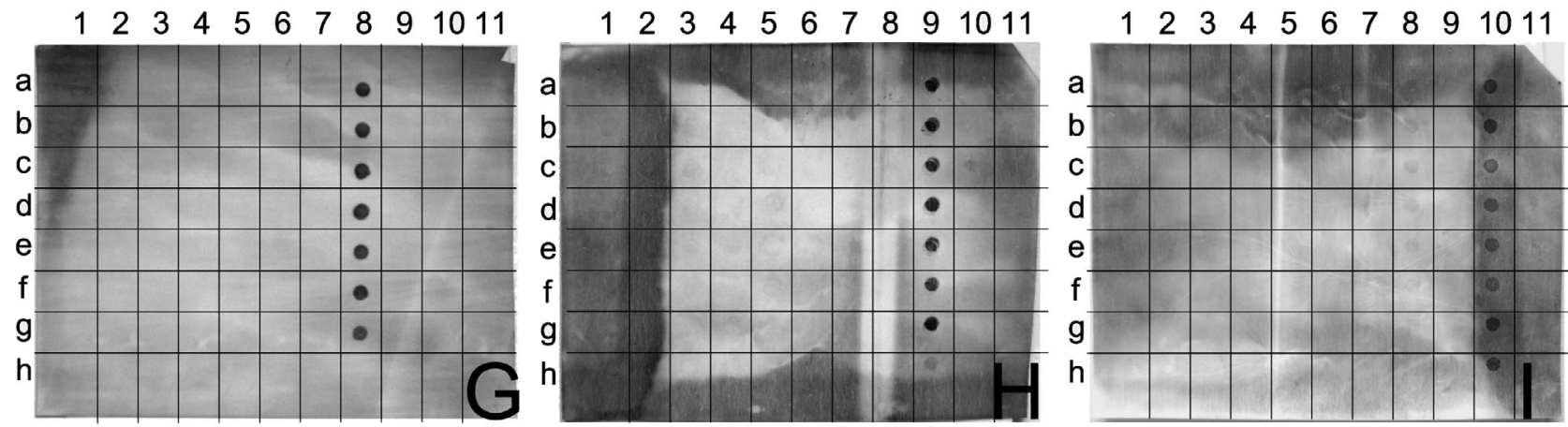

\begin{tabular}{|c|c|c|c|c|c|c|c|c|c|c|c|}
\hline & 1 & 2 & 3 & 4 & 5 & 6 & 7 & 8 & 9 & 10 & 11 \\
\hline $\mathbf{a}$ & M. sp. & N. $n$. & O.e. & C. $g$. & V.p. & T. $r$. & M. b. & C. e. & G. g. & P. m. & T. $t$ \\
\hline b & $M . \mathrm{sp}$. & $N . n$ & O.e. & C. $g$. & $V . p$ & $R . d$. & $M . b$. & C. e. & G. g. & P. $m$ & Co. $g$ \\
\hline c & M. sp. & N. $n$. & O.e. & C. $g$. & $V . p$. & $R . d$. & M. b. & C. e. & G. g. & P. m. & L.c. \\
\hline d & $M . \mathrm{sp}$. & $N . n$. & O.e. & C. g. & $V . p$. & $R . d$. & $M . b$. & C. e. & G. g. & P. m. & A. a. \\
\hline $\mathbf{e}$ & M. sp. & N. $n$. & O.e. & C. $g$. & $V . p$. & $R . d$. & M. b. & C. e. & G. g. & P. m. & S. o. \\
\hline f & M. sp. & & O.e. & C. $g$. & T. $o$. & $R . d$. & $M . b$. & C. e. & G. $g$. & P. m. & \\
\hline $\mathbf{g}$ & M. sp. & & O.e. & & T. $о$. & & M. b. & C. $e$. & G. g. & C. v. & \\
\hline h & M. sp. & & O.e. & & T. $o$. & & & & & C. v. & \\
\hline
\end{tabular}

Veneridae

Pectinidae

Fig. 2. Probe specificity tests through dot-blot. One probe was tested per membrane. A: M yt-18S (Target genus: Mytilus); B: Nuc$18 \mathrm{~S}$ (Target genus: Nucula); C: Ost-ed-18S (Target species: Ostrea edulis); D: Cra-gig-18S (Target species: Crassostrea gigas); E: Ven-18S (Target family: Veneridae); F: M ac-ba-18S (Target species: Macoma balthica); G: Cer-ed-18S (Target species: Cerastoderma edule); H: Gly-18S (Target genus: Glycymeris); I: Pec-18S (Target family: Pectinidae). The table gives the species identities of 18S PCR products blotted onto the membranes, according to their positions. Abbreviations are as follows: M. sp.: Mytilus sp.; N. n.: Nucula nucleus; O. e.: Ostrea edulis; C. g.: Crassostrea gigas; Veneridae (V. p.: Venerupis pullastra; T. o.: Timoclea ovata; T. r.: Tapes rhomboides; R. d.: Ruditapes decussatus); M. b.: Macoma balthica; C. e.: Cerastoderma edule; G. g.: Glycymeris glycymeris; Pectinidae (P. m.: Pecten maximus; C. v.: Chlamys varia); Non target species (T. t.: Tellina tenuis; Co. g.: Corbula gibba; L. c.: Laevicardium crassum; A. a.: Abra alba; S. o.: Spisula ovalis) 
1
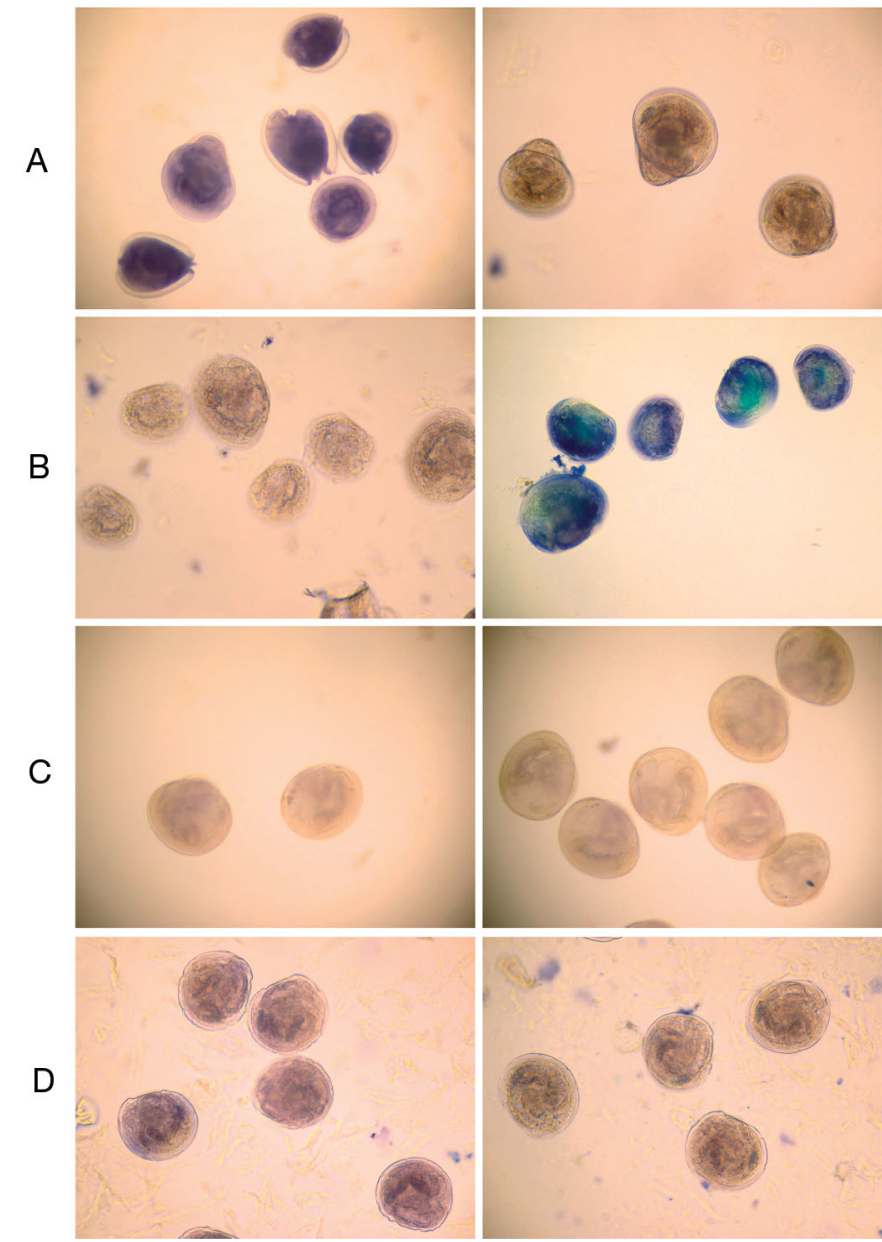

2
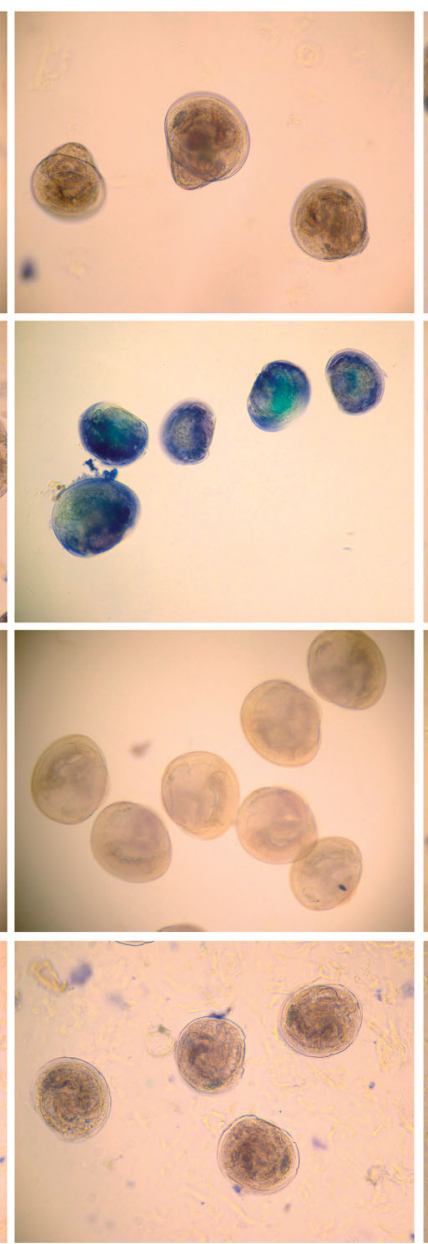

3

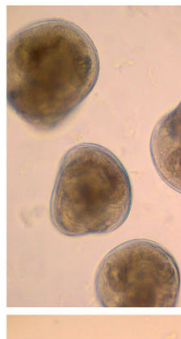

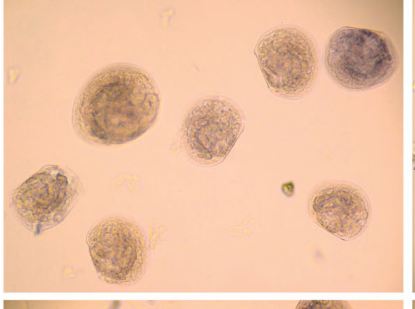
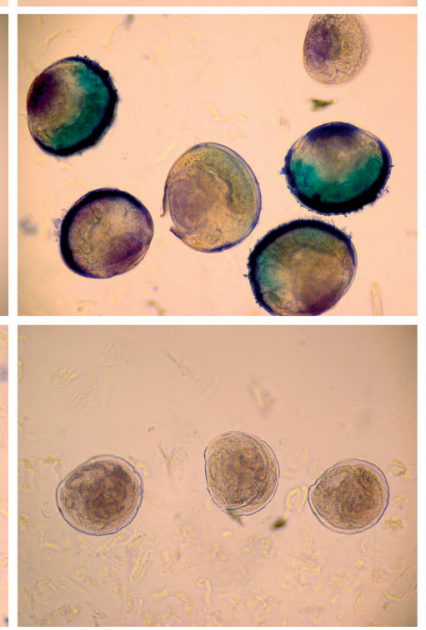

4
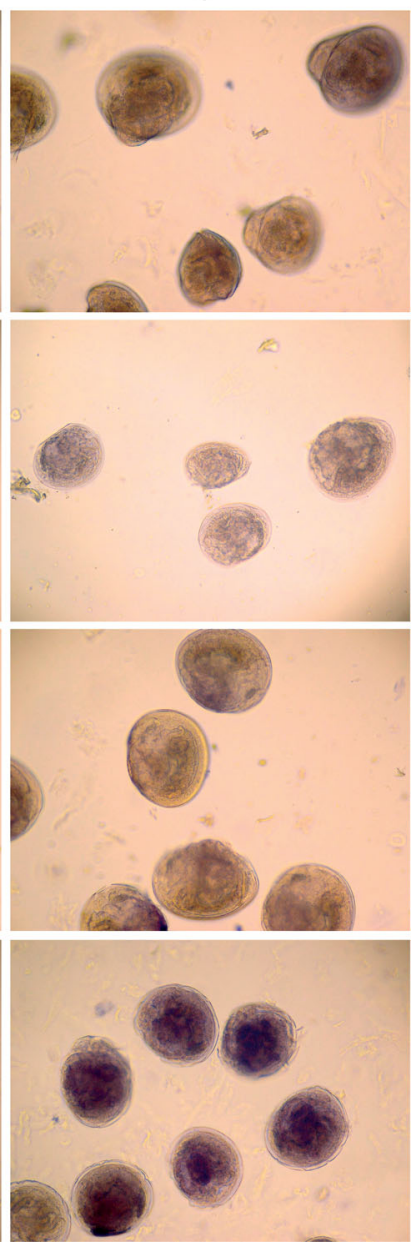

Fig. 3: Specific probes tested on identified larvae through in situ hybridization. A: Crassostrea gigas; B: Pecten maximus; C: Mytilus edulis; D: Ostrea edulis. A, B, C, D hybridized with 1: Cra-gig-18S probe; 2: Pec-18S probe; 3: Myt-18S; and 4: Ost-ed-18S

sionally appeared for all probes used, including the negative probe (Amx1900). It could be distinguished easily from specific staining, which was either homogeneous over the whole larva, or detectable as a dark blue thin line running along the mantle's external edge and the extended velum.

Table 2: Optimized hybridization conditions for 4 specific probes tested on mixed samples containing Crassostrea gigas, Pecten maximus, Mytilus edulis and Ostrea edulis larvae. conc: concentration

\begin{tabular}{|lccc|}
\hline Probe name & $\begin{array}{c}\text { Hybridization } \\
\text { temperature }\left({ }^{\circ} \mathrm{C}\right)\end{array}$ & $\begin{array}{c}\text { Probe conc. } \\
\left(\mathrm{ng} \mu \mathrm{l}^{-1}\right)\end{array}$ & $\begin{array}{c}\% \\
\text { formamide }\end{array}$ \\
\hline Cra-gig-18S & 46 & 0.25 & 10 \\
Pec-18S & 50 & 1.00 & 50 \\
Myt-18S & 50 & 0.10 & 10 \\
Ost-ed-18S & 50 & 1.00 & 50 \\
\hline
\end{tabular}

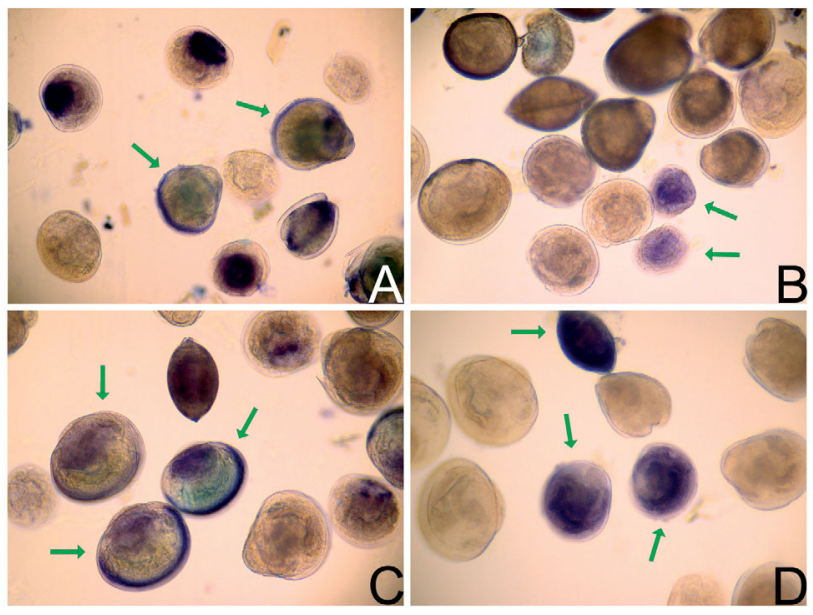

Fig. 4: Specific probes tested through in situ hybridization on samples of mixed larvae of known identity. (A) Cra-gig-18S probe, (B) Pec-18S probe, (C) M yt-18S, (D) Ost-ed-18S. Arrows indicate stained larvae 


\section{DISCUSSION}

In situ hybridization using whole larvae can be used as a reliable identification tool for bivalves. The protocol developed, relying on rRNA-targeted oligonucleotide DNA probes labelled with digoxigenin, has produced consistent results on bivalve larvae isolated from wild plankton samples, as well as on those collected from hatcheries. A partial region of the 185 gene was sufficiently variable to allow design of specific oligo-probes targeting key bivalve species (or higher taxonomic levels) present in North East Atlantic coastal water communities. Probe specificity was experimentally validated. These probes can be used on multi-species assemblages to specifically detect larvae belonging to target species. The value and pitfalls of the method, as well as its potential applications are discussed below.

\section{Value of in situ hybridization as an identification tool for bivalve larvae}

The approach was successfully applied to veligertype bivalve larvae of various sizes isolated from plankton samples collected at different times of the year, and to larvae of different ages from hatcheries. It is also potentially applicable to earlier developmental stages, although this was not tested in the present study. This is a considerable asset for an identification method targeting widely diverse larval stages present simultaneously in aquatic environments, in comparison, for example, with morphological or immunological methods. One of the drawbacks of immunological methodology is that the signature molecule on which the reaction relies on is a protein, the expression level of which varies according to exogenous and endogenous factors (Garland \& Zimmer, 2002).

Specificity is an additional asset of in situ hybridization. Probe specificity tested in silico was experimentally validated through dot blot tests, and for 4 of them through in situ hybridization on whole larvae. The short size of oligonucleotide probes allows high specificity, as a single mismatch in hybridization causes a highly destabilizing effect (Edgcomb et al. 1999). Lack of specificity can be a problem with some identification methods; for instance cross-reaction with non-targeted species has been reported with immunological methods (Paugam et al. 2003).

Through in situ hybridization, each larva can be identified individually. This property confers high sensitivity and a quantitative aspect to the method, resulting in high-resolution data for subsequent applications. These are considerable advantages in compar- ison with molecular approaches relying on DNA extraction and PCR, such as RFLP, multiplex PCR, microsatellites and quantitative PCR. Firstly, PCR failure is common with DNA template extracted from individual larvae, especially after preservation with ethanol or chemical fixatives (Larsen et al. 2005). M oreover, when using as a template DNA extracted from a mixed plankton sample, a bias in estimating numbers of larvae present in a sample through PCR-based methods arises from the fact that various developmental stages are present simultaneously in wild samples, and the quantities of template DNA per larva varies by developmental stage.

In situ hybridization is a potentially high throughput approach, allowing simultaneous screening of large quantities of Iarvae. Larval ecology studies rely on extensive sampling because of the diluted and patchy distribution of larvae in time and space (Garland \& Zimmer 2002). Processing such large samples has been a limiting factor so far (Garland \& Zimmer 2002). In situ hybridization minimizes handling of individual larvae, saving time and limiting potential manipulation error. Throughput could be further enhanced by simultaneous use of differently labelled probes in order to detect several species per sample, as is already the case for phytoplankton and bacterial FISH studies (e.g. Wallner et al. 1993, DeLong et al. 1999). The method could also be coupled advantageously with image-analysis technology, avoiding potential subjectivity for routine screening of samples. Detection and enumeration of stained larvae is a straightforward application of image analysis software (Garland \& Zimmer 2002), and coupling of fluorescent detection with a motorised scanning stage and an image analysis system has already been performed in bacterial studies using immunological methods (de Boer \& Hall 1998). Most of the experimental procedure could be automated, as the larvae (placed in baskets for the in situ protocol) are simply transferred between wells containing different solutions.

An additional advantage of in situ hybridization on whole larvae is that it is non-destructive, preserving the overall larval morphology, and hence providing information on the size and shape of labelled larvae. Conservation of larval morphological characters (such as the umbo of Crassostrea gigas larvae, or hinge shapes), as well as the relative sizes allowed discrimination of species among larvae collected from multi-species assemblages. Such information can be valuable for crosschecking identification using morphological characters, and for biometric indices used in population dynamic studies. This is an advantage over most molecular approaches requiring the extraction of DNA as a first step. 


\section{Potential limitations of in situ hybridization on whole larvae}

Tests conducted through in situ hybridization on whole larvae allowed us to monitor signal sensitivity and specificity on different types of samples including samples containing individuals belonging to the same species (Fig. 2) and those containing individuals from 4 different species mixed together (Fig. 3). These experiments allowed testing the effect of different parameters on the hybridization signal, as well as checking for the occurrence of false positives (non-specific staining) and false negatives (non-staining).

While tests carried out using only 1 larval species showed a specific and sensitive hybridization signal over a range of hybridization conditions, fine adjustments were necessary with samples of mixed species in order to achieve the best signal-to-noise ratio. Successive experiments using artificial meroplankton samples were conducted in order to reach optimal hybridization conditions for each individual probe (Table 2). The observations suggest that the application of each specific probe to wild samples may require experimental optimization. This might be explained by the fact that each oligonucleotide probe has a specific dissociation temperature, depending on its length and base composition (Wallner et al. 1993).

Increasing the hybridization temperature enhanced the stringency of the hybridization, until the dissociation temperature of the probe target hybrid was reached, causing hybridization failure (A mann et al. 1995). Formamide was added to the hybridization buffer at various concentrations, as it improves in situ accessibility by weakening the effects of hydrogen bonds responsible for higher-order structure of ribosomes (Amann et al. 1995). However, high formamide concentrations ( $50 \%$ ) affect conservation of larval morphology. The optimal probe concentration was determined by testing a range of concentrations from 0.1 to $1{\mathrm{ng} \mathrm{Il}^{-1}}^{-1}$ These correspond to intermediate probe concentrations producing an optimal signal to noise ratio in FISH applications (Wallner et al. 1993). At very low probe concentration $\left(0.01 \mathrm{ng}^{-1} \mathrm{l}^{-1}\right)$, the number of probe molecules is not sufficient to bind to all available ribosomes, producing a weak signal, whereas probe concentrations that are too high $\left(20 \mathrm{ng} \mathrm{Hl}^{-1}\right)$ increase nonspecific staining (Wallner et al. 1993).

Altering hybridization conditions avoided non-specific signals on mixed species samples in most cases. More difficulties were experienced with Ostrea edulis larvae, which showed non-specific staining in a range of conditions when different probes were tested, including the negative probe (A mx1900). However, specific and nonspecific staining showed very different patterns and localisations on the larvae. N on-specific staining is com- monly encountered with in situ hybridization on whole invertebrates, and might be due to some particular biochemical structure adsorbing the probe, or to some epitope the anti-Dig antibody recognizes (A. Chipman pers. obs.). The fact that non-specific staining was observed with probes for different nucleotide sequences suggests that it is not caused by mispairing of the probe to nontarget sequences, but by the binding of the conjugated molecules to other cell components (Wallner et al. 1993). On the other hand, specific signals were either homogeneously distributed over the whole larva, or sometimes focused along the mantle exterior edge and the velum (Fig. 3, image C 3 in the matrix). Both organs have key functions in larval development; the edge of the mantle is notably involved in shell secretion, and the velum allows locomotion and acquisition of food (Ruppert \& Barnes 2004). These particular areas are thus intensely metabolically active, and are likely to contain numerous ribosomes, targets of the oligonucleotide probes. A number of studies using FISH, especially on single-cell organisms, report that metabolic condition has a strong influence on the intensity of signal from rRNAtargeting oligonucleotide probes (see Amann et al. 1995 for review). This might explain a predominant signal in the most metabolically active cells of the larva.

False negatives were seldom encountered, and were restricted to Mytilus edulis larvae hybridized with the M yt-18S and eukaryotic (EUK516) probes. Problems of target accessibility have been reported in FISH applications on microorganisms; these arise from cell wall prevention of probe penetration into the cytoplasm (Amann et al. 1995). In order to avoid limited target accessibility caused by sealed mollusc shells, we used a solution of $\mathrm{M} \mathrm{gCl}_{2}$ before fixing the larvae, allowing adductor muscles, responsible for closing of the valves, to relax, leaving the shell open for the subsequent hybridization procedure. Meanwhile, shell morphology was kept intact for subsequent visual inspection. The effect of the reagent could be checked on larvae with a protruding velum from between the valves. As false negative cases always corresponded to larvae in which the velum was retracted and the valves closed, a problem might have occurred during larval fixation. An alternative hypothesis is that some of the larvae may have been in very poor metabolic condition, and that their unusually low cellular ribosome content resulted in a signal too weak to be detected.

\section{Relevance of the 18S rRNA-targeted probes for species identification via in situ hybridization}

Probes targeting rRNAs have been widely used for identifying and quantifying a range of organisms, 
even single bacterial cells, because ribosomes are highly abundant in living cells, resulting in an intense signal per cell (A mann et al.1995). This high sensitivity, compared to probes targeting genes (even those with multiple copies) or high transcript levels, is a considerable asset. Moreover, rRN A is less labile than mRNA (Cai \& Winkler 1993), which also contributes to a higher concentration of targets. Initial tests were carried out using a variety of probes, viz. mitochondrial COI DNA and RNA probes. No signal was detected, despite tentative hybridization optimizations. This might be due to a signal that is too weak for detection by colorimetry. An additional difficulty might arise from the fact that only extra-mitochondrial mtRNAs tend to be targeted through in situ hybridization, because of the inability of the probes to penetrate inner mitochondrial membranes (A mikura et al. 1996, Ogawa et al. 1999).

A further advantage of the 18S rRNA gene as a template for designing specific probes is the presence of variable regions allowing bivalve species discrimination (Bell \& Grassle 1998, Frischer et al. 2000, Larsen et al. 2005). High inter-specific variation between taxa coupled with an absence of variation at the intraspecific level has been reported for the $18 \mathrm{~S}$ gene across many metazoan phyla (Abouheif et al. 1998). The availability of both conserved and variable regions, allowing the design of universal primers for subsequent amplification of variable regions of the $18 \mathrm{~S}$ gene, make it a widely used marker for species identification purposes, such as DNA barcoding projects (e.g. Floyd et al. 2002, Bhadury et al. 2006). Finally, the existence of databases of ribosomal sequences (e.g. The European Ribosomal RNA Database: www.psb. ugent.be/rRNA) facilitates the assembly of homologous sequence databases required for the design of specific probes.

\section{Potential applications of the method}

Many aspects of the larval stages of marine benthic invertebrates remain poorly understood. The planktonic stage is nevertheless a crucial parameter for consideration at the population and ecosystem level, shaping genetic structures and determining the evolution of populations and eventually communities. Processes governing larval dispersal and recruitment and their relative importance and interactions are not yet fully elucidated. Physical, chemical and ecological processes have been reported as important parameters, together with active larval behaviour at small spatial scales. Studies of larval distributions have so far been hampered by the difficulty of accurately identifying Iarvae, especially those that are small. Unambiguous, straightforward and high-throughput identification methods are needed to meet the extreme requirements of field-based studies relying on intensive sampling programmes over long periods of time. This is a prerequisite towards the elucidation of larval migration patterns, recruitment processes, and predator/prey population dynamics. In situ hybridization on whole larvae could be used in multidisciplinary studies, providing new insights into population connectivity over a range of scales (e.g. Gilg \& Hilbish 2003, Arnold et al. 2005). The method can be easily implemented in any biological laboratory; it does not need costly equipment or consumables and does not require staff to go through advanced specific training. The methodology is flexible. Several steps can be automated, and data acquisition can be made faster through a motorised scanning microscope stage and image analysis technology.

More specific applications include long- or shortterm monitoring of multiple or single target species, such as species of commercial interest, bio-indicator, rare or invasive species. Routine screening of plankton samples for biodiversity studies will require the generation of sub-samples to be tested with different probes. Sufficiently large samples would be necessary for subsequent testing of the statistical significance of the results. Alternatively, different probes labelled with different fluorescent dyes could be used simultaneously on wild samples, as is the case for microbial studies (Wallner et al. 1993). Such an approach, increasing the throughput of the method, would, however, require significant protocol optimization. Nested probes, designed for different taxonomic levels and applied to sub-samples of plankton in an ordered topto-bottom approach, could offer another alternative approach, as previously implemented through FISH with rRNA targeted oligo-probes on microbial samples (Amann et al. 1995). The results obtained with highlevel probes allow the selection of probes with narrower specificity designed for the next lowest taxonomic level, providing increasingly refined information on community diversity and composition.

Acknowledgements. We thank the crew of the RV Mysis for their help with the sampling. The identified larvae were kindly provided by $C$. Mingant (Station Expérimentale Ifremer d'Argenton), M. Muzellec (Ecloserie du Tinduff) and P. Boudry (Laboratoire Ifremer La Tremblade) (France). We thank staff of M. Akam's laboratory, University Museum of Zoology and from the groups Plancton Océanique and EGPM, Station Biologique de Roscoff for helpful discussion on protocol development. F. Viard and anonymous reviewers helped improve the manuscript. Figures were edited with Inkscape and The GIMP by A.Vitry. This project and M.L.G.V.'s fellowship was funded by Marine Genomics Europe (Contract Nb: GOCE-CT-2004-505403). This project also benefited from support by PNEC-Chantier 'Baie du mont Saint Michel'. 


\section{LITERATURE CITED}

Abouheif E, Zardoya R, Meyer A (1998) Limitations of metazoan $18 S$ rRNA sequence data: implications for reconstructing a phylogeny of the animal kingdom and inferring the reality of the Cambrian explosion. J Mol Evol 47: 394-405

Amann RI, Binder BJ , Olson RR, Chisholm SW, Devereux R, Stahl DA (1990) Combination of $16 S$ rRNA-targeted oligonucleotide probes with flow cytometry for analysing mixed microbial populations. Appl Environ Microbiol 56: 1919-1925

Amann RI, Ludwig W, Schleifer KH (1995) Phylogenetic identification and in situ detection of individual microbial cells without cultivation. Microbiol Rev 59:143-169

A mikura R, Kobayashi S, Saito H, Okada M (1996) Changes in subcellular localization of mtlrRNA outside mitochondria in oogenesis and early embryogenesis of Drosophila melanogaster. Dev Genes Evol 38:489-498

André C, Lindegarth M, J onsson PR, Sundberg P (1999) Species identification of bivalve larvae using random amplified polymorphic DNA (RAPD): differentiation between Cerastoderma edule and C. lamarcki. J M ar Biol Assoc UK 79:563-565

Arnold WS, Hitchcock GL, Frischer ME, Wanninkhof R, Sheng YP (2005) Dispersal of an induced larval cohort in a coastal lagoon. Limnol Oceanogr 50:587-597

Bell J L, Grassle J P (1998) A DNA probe for identification of larvae of the commercial surfclam (Spisula solidissima). Mol Mar Biol Biotechnol 7:127-137

Bhadury P, Austen M, Bilton DT, Lambshead PJ D, Rogers AD, Smerdon GR (2006) Development and evaluation of a DNA-barcoding approach for the rapid identification of nematodes. Mar Ecol Prog Ser 320:1-9

Cai J , Winkler HH (1993) Identification of tlc and gltA mRNAs and determination of in situ RNA half-life in Rickettsia prowasekii. J Bacteriol 175:5725-5727

Comtet T, J ollivet D, Khripounoff A, Segonzac M, Dixon DR (2000) Molecular and morphological identification of settlement-stage vent mussel larvae, Bathymodiolus azoricus (Bivalvia: Mytilidae), preserved in situ at active vent fields on the Mid-Atlantic Ridge. Limnol Oceanogr 45: 1655-1661

de Boer SH, Hall J W (1998) An automated microscope system for estimating the population of Corynebacterium sepedonicum cells labeled with monoclonal antibodies in immunofluorescence. Can J Plant Path 10:215-220

DeLong EF, Trent Taylor L, Marsh TL, Preston CM (1999) Visualization and enumeration of marine planktonic Archaea and bacteria by using polyribonucleotide probes and fluorescent in situ hybridization. Appl Environ M icrobiol 65:5554-5563

Edgcomb VP, McDonald J H, Devereux R, Smith DW (1999) Estimation of bacterial cell numbers in humic acid-rich salt marsh sediments with probes directed to $16 \mathrm{~S}$ ribosomal DNA. Appl Environ Microbiol 65:1516-1523

Fabioux C, Huvet A, LeLong C, Robert R, Pouvreau S, Daniel JY, M ingant C, Le Pennec M (2004) Oyster vasa-like gene as a marker of the germline cell development in Crassostrea gigas. Biochem Biophys Res Commun 320: 592-598

Floyd R, Abebe E, Papert A, Blaxter M L (2002) M olecular barcodes for soil nematode identification. Mol Ecol 11: 839-850

Frischer ME, Danforth J M, Tyner LC, Leverone J R, M arelli DC, Arnold WS, Blake NJ (2000) Development of an Argopecten-specific 18S rRNA targeted genetic probe.
Mar Biotechnol 2:11-20

Frischer ME, Hansen AS, Wyllie J A, Wimbush J, Murray J, Nierzwicki-Bauer SA (2002) Specific amplification of the 18S rRNA gene as a method to detect zebra mussel (Dreissena polymorpha) larvae in plankton samples. Hydrobiologia 487:33-44

Fuller SC, Lutz RA (1989) Shell morphology of larval and post-larval mytilids from the north-western Atlantic. J M ar Biol Assoc UK 69:181-218

Garland ED, Zimmer CA (2002) Techniques for the identification of bivalve larvae. M ar Ecol Prog Ser 225:299-310

Gilg MR, Hilbish TJ (2003) The geography of marine larval dispersal: coupling genetics with fine-scale physical oceanography. Ecology 84:2989-2998

Haygood M G, Davidson SK (1997) Small-subunit rRNA genes and in situ hybridization with oligonucleotides specific for the bacterial symbionts in the larvae of the bryozoan Bugula neritina and proposal of 'Candidatus Endobugula sertula'. Appl Environ Microbiol 63:4612-4616

Hosoi M, Hosoi-Tanabe S, Sawada H, Ueno M, Toyohara H, Hayashi I (2004) Sequence and polymerase chain reaction-restriction fragment length polymorphism analysis of the large subunit rRN A gene of bivalve: simple and widely applicable technique for multiple species identification of bivalve larvae. Fish Sci 70:629-637

Larsen J B, Frischer ME, Rasmussen LJ, Hansen BW (2005) Single-step nested multiplex PCR to differentiate between various bivalve larvae. M ar Biol 146:1119-1129

Lorenzo-Abalde S, Gonzales-Fernandez A, de Miguel Villegas E, Fuentes J (2005) Two monoclonal antibodies for the recognition of Mytilus spp. larvae: studies on cultured larvae and tests on plankton samples. Aquaculture 250: 736- 747

Loy A, Horn M, Wagner M (2003) ProbeBase-an online resource for rRNA-targeted oligonucleotide probes. Nucleic Acids Res 31:514-516

Moon-van der Staay SY, De Watcher R, Vaulot D (2001) Oceanic $18 \mathrm{~S}$ rDNA sequences from picoplankton reveal unsuspected eukaryotic diversity. Nature 409:607-610

Morgan TS, Rogers AD (2001) Specificity and sensitivity of microsatellite markers for the identification of larvae. Mar Biol 139:967-973

Nederbragt AJ , Van Loon AE, Dictus WJ AG (2002) Expression of Patella vulgata orthologs of engrailed and $d p p$ $B M P 2 / 4$ in adjacent domains during molluscan shell development suggests a conserved compartment boundary mechanism. Dev Biol 246:341-355

Ogawa M, Amikura R, Akasaka K, Kinoshita T, Kobayashi S, Shimada H (1999) A symmetrical distribution of mitochondrial rRNA into small micromeres of sea urchin embryos. Zool Sci 16:445-451

Paugam A, Le Pennec M , M arhic A, André-Fontaine G (2003) Immunological in situ determination of Pecten maximus larvae and their temporal distribution. J Mar Biol Assoc UK 83:1083-1093

Pie MR, Boeger WA, Patella L, Falleiros RM (2006) A fast and accurate molecular method for the detection of larvae of the golden mussel Limnoperma fortunei (Mollusca: Mytilidae) in plankton samples. J Molluscan Stud 72: 218-219

Pozhitkov AE, Tautz D (2002) An algorithm and program for finding sequence specific oligo-nucleotide probes for species identification. BMC Bioinformatics 3:9

Rees CB (1950) The identification and classification of lamellibranch larvae. Hull Bull Mar Ecol 3:73-104

Ruppert EE, Barnes RD (2004) Invertebrate zoology, 7th edn Saunders College Publishing, Philadelphia, PA 
Schmid M, Schmitz-Esser S, J etten M, Wagner M (2001) 16S235 rDNA intergenic spacer and 235 rDNA of anaerobic ammonium-oxidizing bacteria: implications for phylogeny and in situ detection. Environ M icrobiol 3:450-459

Simon N, Campbell L, Ornolfsdottir E, Groben R, Guillou L, Lange M, Medlin LK (2000) Oligonucleotide probes for the identification of three algal groups by dot-blot and fluorescent whole-cell hybridization. J Euk Microbiol 47: 76-84

Tyrrell J V, Bergquist PR, Saul DJ , M acKenzie L, Bergquist PL (1997) Oligonucleotide probe technology as applied to the study of harmful algal blooms. N Z J Mar Freshw Res 31: 551-560

Ueki T, Yoshida S, Marikawa Y, Satoh N (1994) Autonomy of

Editorial responsibility: Matthias Seaman (Assistant Editorin-Chief), Oldendorf/Luhe, Germany expression of epidermis-specific genes in the ascidian embryo. Dev Biol 164:207-218

Wallner G, Amann RI, Beisker W (1993) Optimizing fluorescent in situ hybridization with rRNA-targeted oligonucleotide probes for flow cytometric identification of microorganisms. Cytometry 14:136-143

Wood AR, Beaumont AR, Skibinski DOF, Turner G (2003) Analysis of a nuclear-DNA marker for species identification of adults and larvae in the Mytilus edulis complex. J Molluscan Stud 69:61-66

Yaguchi S, Katow H (2003) Expression of tryptophan 5-hydroxylase gene during sea urchin neurogenesis and role of serotonergic nervous system in larval behavior. J Comp Neurol 466:219-229

Submitted: November 10, 2006; Accepted: January 30, 2007 Proofs received from author(s): July 17, 2007 